\title{
Analisis Potensi Ketersediaan Tanaman Bambu dan Pemasaran Kerajinan Bambu di Desa Kayubihi Kecamatan Bangli Kabupaten Bangli
}

\author{
AYU RATIH PRATIWI, I NYOMAN GEDE USTRIYANA, \\ A.A.A WULANDIRA SAWITRI DJELANTIK \\ Program Studi Agribisnis, Fakultas Pertanian, Universitas Udayana \\ Jl. PB. Sudirman Denpasar 80233 \\ Email: pratiwiratih80@gmail.com \\ gede_ustriyana@unud.ac.id
}

\begin{abstract}
The Potential Analysis Availability Of Bamboo Plants and The Marketing of Bamboos Product at Kayubihi Village, Bangli Distric, Bangli Regency.
\end{abstract}

Analysis of the potential availability of bamboo plants in Kayubihi Village, Bangli Subdistrict, Bangli Regency is divided into two analyzes, namely the analysis of potential availability and marketing analysis. Analysis of potential availability to know the potency of bamboo found in Kayubihi Village while for marketing seen marketing channel, marketing margin, and profit margin with the election of three main products produced by Kayubihi Village. Types of data used in this study are qualitative data and quantitative data and data sources obtained from primary data and secondary data. Data collection methods used there are three namely Library research, field research and study literature. The population in this study were 50 bamboo farmers who were also bamboo craftsmen. Data analysis was done descriptively quantitative and qualitative descriptive. The results showed that the analysis of potential availability with five types of bamboo plants is under 200 clumps/ha which means not yet potential. Bamboo is processed into handicrafts and marketed for marketing the main products are sokasi, cakes basket, and coocked rice basked. Each product has three marketing channels. The most profit margin obtained in each marketing channel is at producer level. The shortest marketing margin in each channel because it is directly to the consumer.

Keywords : potential, marketing, bamboo

\section{Pendahuluan}

\subsection{Latar Belakang}

Perhatian dunia terhadap tanaman bambu akhir - akhir ini tumbuh dengan pesat seiring dengan kepedulian masyarakat terhadap praktek pengelolaan sumber daya alam yang berkelanjutan. Tanaman bambu merupakan salah satu jenis yang ideal untuk pemanfaatan yang berkelanjutan (Rijai, 2003). Potensi bambu dalam menopang hutan dinilai ekonomis di masa depan. Hutan sebagai sumber utama penghasil kayu dari waktu ke waktu kondisinya sudah sangat memperihatinkan. Keadaan ini disebabkan adanya tindakan eksploitasi dengan cara yang sangat tidak bijaksana, tanpa 
memperhatikan keberlangsungan dan kelestarian hutan itu sendiri (Gunardja, 1995). Sekitar 1500 jenis bambu di dunia lebih dari 140 jenis tumbuh di Indonesia (Batubara, 2002).

Sepuluh tahun terakhir perkembangan industri kerajinan rumah tangga yang menggunakan bahan baku dari bambu semakin pesat di Bali (Arinasa Ketut dan Nyoman Peneng, 2013). Hasil sensus pertanian dari Badan Pusat Stastistik jumlah tanaman bambu yang diusahakan menurut kabupaten/kota dan jenis tanaman di Provinsi Bali tahun 2013 adalah tercatat di Provinsi Bali sebanyak 6.314.57 ribu rumpun Kabupaten Bangli merupakan wilayah yang paling banyak terdapat tanaman bambu sebanyak 2.813.62 ribu rumpun sebaliknya Kota Denpasar memiliki jumlah tanaman bambu paling sedikit yaitu sebanyak 282 rumpun saja (BPS, 2013).

Keadaan geografis Kabupaten Bangli merupakan daerah pertanian yang cocok untuk budidaya bambu. Perkembangan potensi industri bambu di Bangli semakin meningkat dengan banyaknya unit usaha yang dimiliki mampu menambah pendapatan kota Bangli. Kota Bangli lebih mempertahankan potensi bambu yang berkembang selain perkembangan potensi industri bambu di Bangli hasil data dari Dinas Pertanian Bangli Kabupaten Bangli adalah Desa Kayubihi menghasilkan produksi bambu pada tahun 2013 sebanyak 9.508 .000 batang bambu dan meningkat di tahun 2014 sebanyak 10.003.520 batang bambu untuk tahun 2015 meningkat kembali sebanyak 10.047.000 batang bambu (Dinas Pertanian Bangli Kabupaten Bangli, 2016)

Desa Kayubihi memiliki luas lahan tanaman bambu $125 \mathrm{Ha}$ hasil produksi dan dijual menjadi kerajinan bambu sehingga para penduduk Desa Kayubihi bermata pencarian sebagai petani bambu atau pengrajin bambu. Pemasaran bambu yang diolah menjadi kerajinan bambu di Desa Kayubihi sudah ekspor ke berbagai negara seperti Perancis dan Amerika. Pemasaran di Bali Desa Kayubihi memasarkan produknya ke seluruh Bali.

\subsection{Tujuan penelitian}

1. Menganalisis potensi ketersediaan tanaman dan jenis-jenis bambu di Desa Kayubihi, Kecamatan Bangli, Kabupaten Bangli.

2. Menganalisis proses tanaman bambu menjadi produk kerajinan di Desa Kayubihi, Kecamatan Bangli, Kabupaten Bangli.

3. Menganalisis saluran pemasaran, marjin pemasaran, dan marjin keuntungan produk-produk kerajinan bambu di Desa Kayubihi, Kecamatan Bangli, Kabupaten Bangli.

\section{Metode Penelitian}

\subsection{Lokasi dan Waktu Penelitian}

Penelitian ini dilakukan di Desa Kayubihi, Kecamatan Bangli, Kabupaten Bangli, penentuan lokasi ini dipilih dengan cara purposive. Penelitian ini dilaksanakan pada bulan Februari sampai dengan Mei 2017.

\subsection{Jenis dan Sumber Data}

Jenis data yang digunakan dalam penelitian ini dibagi menjadi dua yaitu data kualitatif yaitu data yang bukan berbentuk angka namun melalui wawancara, observasi, analisis dokumen, dan diskusi terfokus. Data kuantitatif adalah data yang berupa angka hasil dari suatu pengukuran, observasi, dan membilang yang dapat dianalisis. 
Berdasarkan sumbernya, data yang digunakan pada penelitian ini terdiri dari data primer yang diperoleh melalui wawancara dan data sekunder yang diperoleh melalui studi literatur dan data yang berbagai literatur yang berhubungan dengan penelitian ini.

\subsection{Metode Pengumpulan Data}

Pengumpulan data dalam penelitian ini secara langsung pada lokasi penelitian dengan tiga cara yaitu library research yang dilakukan melalui publikasi dan elektronik lainnya, field research melakukan wawancara dan observasi sedangkan untuk studi literature mencari data yang berasal dari instansi yang terkait dengan penelitian ini, serta dari sumber internet yang terdapat informasi-informasi yang sesuai dengan penelitian ini.

\subsection{Populasi dan Sampel Penelitian}

Populasi merupakan kumpulan individu dengan kualitas dan ciri-ciri yang diterapkan, sedangkan sampel merupakan bagian individu dari jumlah dan karakteristik yang dimiliki populasi (Antara, 2006). Cara untuk menentukan berapa minimal sampel yang dibutuhkan dapat digunakan rumus slovin (Sevilla, 1994). Populasi dalam penelitian ini adalah 50 petani bambu yang sekaligus menjadi pengerajin bambu. Teknik sampling yang digunakan dalam penelitian ini adalah random sampling.

\subsection{Variabel dan Indikator}

Variable yang pada penelitian ini ada dua yaitu analisis potensi dan pemasaran dimana pengukurannya dilihat dari kualitatif dan kuantitatif. Data kualitatif penelitian ini yaitu jenis bambu, proses produksi, dan lembaga pemasaran sedangkan untuk kuantitatif yaitu margin pemasaran dan margin keuntungan.

\subsection{Metode Analisis Data}

\subsubsection{Analisis potensi}

Kegiatan yang dilakukan mengetahui potensi bambu dilihat dari dua aspek dimana dari potensi dan produksi untuk potensi tanaman bambu mengenai luasan tanaman bambu, hasil panen/hektar tanaman bambu dan jenis tanaman bambu sedangkan untuk produksi mengenai proses pembuatan bambu menjadi kerajinan bambu. Rumus yang digunakan untuk menghitung potensi rumpun tiap hektar menurut Departemen Kehutanan dan Perkebunan (1998), dengan rumus :$$
\mathrm{Kr}=\sum_{\mathrm{i}=1}^{\mathrm{n}} \mathrm{Bi}
$$$$
\mathrm{Kr}=\frac{\sum_{\mathrm{i}=1} \mathrm{Bi}}{\sum_{\mathrm{i}=1}^{\mathrm{n}} \mathrm{Ri}}
$$

Dimana : $\sum_{\mathrm{i}=1}^{\mathrm{n}} \mathrm{R}$

$\mathrm{Kr}=$ jumlah batang tiap rumpun suatu jenis bambu

$\mathrm{Bi}=$ Jumlah batang suatu jenis bambu tiap jalur ke $\mathrm{i}$

$\mathrm{Ri}=$ Jumlah rumpun suatu jenis bambu tiap jalur ke $\mathrm{i}$
} 


\subsubsection{Saluran pemasaran}

Saluran pemasaran untuk mengetahui saluran pemasaran yang digunakan oleh pengrajin bambu dalam memasarkan produk kerajinan bambu yang dihasilkan ke konsumen. Dianalisis secara analisis deskriptif kualitatif.

\subsubsection{Marjin pemasaran}

Menurut Kohls dan Joseph (1998), marjin pemasaran adalah perbedaan jumlah yang harus dibayar oleh konsumen untuk produksi akhir dengan jumlah yang diterima oleh produsen. Marjin pemasaran dapat dirumuskan sebagai berikut :

$$
\mathrm{MP}=\mathrm{HK}-\mathrm{HP}
$$

Keterangan :

MP = Marjin pemasaran

HK = Harga beli konsumen

$\mathrm{HP}$ = Harga jual produk

\subsubsection{Marjin keuntungan}

Marjin keuntungan digunkan untuk melihat seberapa besar keuntungan ditiap lembaga yang diperoleh setiap saluran pemasaran dengan rumus :

$$
\% \mathrm{I}=\mathrm{I} / \mathrm{HP} \times 100 \%
$$

Dimana :

I $\quad=$ Marjin keuntungan

$\mathrm{HP} \quad=$ Harga penjualan

\section{Hasil dan Pembahasan}

\subsection{Analisis Potensi}

Desa Kayubihi, Kecamatan Bangli, Kabupaten Bangli memiliki luas 1.846,95 Ha dan memiliki lahan bambu seluas 125 Ha dari luasan total desa memiliki Sembilan banjar dinas yang sebagian besar merupakan pengrajin bambu. Desa Kayubihi memiliki potensi sebagai desa kerajinan dilihat dari banyaknya kerajinan dari bambu yang sudah dihasilkan oleh para pengerajin bambu.

\subsubsection{Jenis bambu di Desa Kayubihi}

Desa Kayubihi memiliki lima jenis tanaman bambu yang sudah ada sejak jaman dahulu. Panen bambu yang dilakukan di desa ini setiap setahun dua kali atau setiap tiga sampai lima bulan dengan jumlah volume hasil panen.

1. Bambu Tali

Bambu Tali (Gigantochloa apus) merupakan jenis bambu yang tersebar di Indonesia dan Asia tropis. Bambu ini banyak diusahakan untuk bahan baku pembuatan kerajinan tangan. Bambu di Desa Kayubihi memiliki luas lahan 26,32 ha dengan total rumpun sebanyak 2.836 rumpun. Banyaknya total tanaman bambu tali adalah 111.925 batang bambu. Hasil data potensi bambu tali di Desa Kayubihi terdapat sebanyak 113 
rumpun/ha terdapat 4.536 batang tiap hektarnya dan Jumlah Batang Tiap Rumpun (KR) bambu tali di Desa Kayubihi sebanyak 40 batang tiap rumpun/hektar.

\section{Bambu Betung}

Bambu Betung (Dendrocalamus asper) banyak digunakan dalam industri kerajinan rumah tangga dibidang kontruksi, pertanian, perikanan, makanan/sayuran, dan sarana upacara Agama Hindu. Luas lahan bambu betung 8,77 ha dengan total rumpun bambu sebanyak 1.129 rumpun. Luasan total tanaman bambu terdapat sebanyak 45.836 batang bambu. Pengukuran yang dilakukan dilapangan terdapat sebanyak 129 rumpun/ha dimana terdapat 5.226 batang tiap hektarnya dan Jumlah Batang Tiap Rumpun (KR) bambu buluh lengis pada Desa Kayubihi adalah sebanyak 41 batang tiap rumpun/hektarnya.

3. Bambu Jajang Aya

Bambu Jajang Aya merupakan salah satu jenis bambu endemik Bali. Bambu ini terbatas penyebarannya untuk di Provinsi Bali banyak terdapat di Kabupaten Bangli dan Karangasem. Bambu Jajang Aya di Desa Kayubihi memiliki luas lahan 7,84 ha, dengan total rumpun bambu sebanyak 1.208 rumpun. Pengukuran yang dilakukan di lapangan terdapat sebanyak 68 rumpun/ha dimana terdapat 3.218 batang tiap hektarnya dan Jumlah Batang Tiap Rumpun (KR) bambu jajang aya di Desa Kayubihi adalah sebanyak 46 batang tiap rumpun/hektarnya.

\section{Bambu Buluh Gading}

Bambu Buluh Gading ini memiliki rumpun rapat dan tegak, rembung kuning atau hijau pelepah buluh coklat dan tertutup rapat dan tegak, rembung kuning atau hijau pelepah buluh coklat dan tertutup bulu coklat. Luas lahan tanaman bambu buluh gading 7,01 ha, dengan total rumpun bambu sebanyak 832 rumpun. Terdapat banyaknya tanaman bambu 33.356 batang bambu. Data potensi bambu buluh gading yang terdapat di Desa Kayubihi terdapat sebanyak 117 rumpun/ha dimana terdapat 4.758 batang tiap hektarnya dan Jumlah Batang Tiap Rumpun (KR) Bambu Buluh Gading sebanyak 40 batang tiap rumpun/hektar.

\section{Bambu Buluh Lengis}

Bambu Buluh Lengis (Schixostochyum lima (Blanco) Merr) di Desa Kayubihi menggunakan buluhnya untuk membuat berbagai kerajinan rumah tangga, terutama gedeg. Luas lahan bambu buluh lengis adalah 7,84 ha, dengan total rumpun bambu sebanyak 953 rumpun. Luasan total tanaman bambu tersebut terdapat sebanyak 38.738 batang bambu. Pengukuran dilapangan pada tanaman bambu buluh gading yaitu terdapat sebanyak 121 rumpun/ha dimana terdapat 4.941 batang tiap hektarnya dan Jumlah Batang Tiap Rumpun (KR) bambu buluh lengis pada Desa Kayubihi adalah sebanyak 41 batang tiap rumpun/hektar.

Hasil data potensi kelima jenis tanaman bambu di Desa Kayubihi dan sesuai dengan Keputusan Menteri Kehutanan (2009) dalam (Ridho, 2010) mengatakan daerah yang memiliki potensi ketersediaan tanaman bambu sebanyak 200 rumpun/ha dikategorikan berpotensi. Jenis tanaman bambu yang ada di Desa Kayubihi memiliki potensi dibawah 200 rumpun/ha yang artinya belum belum berpotensi. 


\subsubsection{Proses pembuatan sokasi}

Proses pembuatan sokasi di Desa Kayubihi adalah melakukan pemilihan bambu terlebih dahulu, dipanen, diangkut, dilakukan pembersihan kulit, pengecatan, penjemuran, penganyaman dan yang terakhir adalah desain sesuai dengan permintaan konsumen.

\subsubsection{Proses pembuatan tempat kue dan tempat nasi}

Proses pembuatan tempat kue dan tempat nasi prosesnya sama hanya saja bentuknya saja yang berbeda, pemilihan bambu, panen, pengangkutan, pembersihan kulit, pemotongan, penganyaman, penjemuran, dan pengecatan.

\subsection{Pemasaran}

Hampir sebagian masyarakat di Desa Kayubihi merupakan pengerajin bambu sehingga tidak sedikit yang bergantung dengan menjual kerajinan bambu untuk keberlangsungan hidup sehari-hari mereka.

\subsubsection{Lembaga pemasaran}

Lembaga pemasaran yang terlibat dalam penelitian ini adalah produsen, pengepul, pedagang besar, dan pengecer.

\subsubsection{Saluran pemasaran}

Saluran pemasaran sokasi di Desa Kayubihi yaitu

a : produsen - konsumen

$\mathrm{b}$ : produsen - pengepul - pengecer - konsumen

c : produsen - pengepul - pedagang besar - pengecer - konsumen

Saluran pemasaran tempat kue yaitu

a : produsen - konsumen

$\mathrm{b}$ : produsen - pengepul - konsumen

$c$ : produsen - pengepul - pedagang besar - pengecer - konsumen

Saluran pemasaran tempat nasi yaitu

a : produsen - konsumen

$\mathrm{b}$ : produsen - pengepul - kosumen

$\mathrm{c}$ : produsen - pengepul - pedagang besar - pengecer - konsumen

\subsubsection{Marjin pemasaran dan marjin keuntungan}

Analisis marjin pemasaran digunakan untuk melihat selisih harga yang dibayar konsumen dengan harga dari produsen. Marjin keuntungan dinikmati masing- masing pemasaran yang terlibat. 
Tabel 1.

Marjin Pemasaran dan Marjin Keuntungan pada Produk Sokasi di Desa Kayubihi, Kecamatan Bangli, Kabupaten Bangli.

\begin{tabular}{|c|c|c|c|c|}
\hline \multirow[b]{2}{*}{ Pelaku Pasar } & \multirow[b]{2}{*}{ Jenis Harga } & \multicolumn{3}{|c|}{ Distribusi Harga pada Pola Tataniaga (Rp/Produk) } \\
\hline & & Saluran I & Saluran II & Saluran III \\
\hline \multirow[t]{3}{*}{ Produsen } & Harga Jual & 160.000 & 74.000 & 74.000 \\
\hline & Marjin keuntungan & 122.230 & 36.230 & 46.230 \\
\hline & $\begin{array}{l}\text { Persentase marjin } \\
\text { keuntungan }\end{array}$ & $76,39 \%$ & $48,95 \%$ & $55,03 \%$ \\
\hline \multirow[t]{4}{*}{ Pengepul } & Harga beli & & 74.000 & 74.000 \\
\hline & Marjin keuntungan & & 48.240 & 49.240 \\
\hline & Persentase marjin & & $39,21 \%$ & $39,70 \%$ \\
\hline & keuntungan & & & \\
\hline \multirow{4}{*}{$\begin{array}{l}\text { Pedagang } \\
\text { besar }\end{array}$} & Harga beli & & & 124.000 \\
\hline & Marjin keuntungan & & & 18.200 \\
\hline & Persentase marjin & & & $13,00 \%$ \\
\hline & keuntungan & & & \\
\hline \multirow[t]{3}{*}{ Pengecer } & Harga beli & & 123.000 & 143.000 \\
\hline & Marjin keuntungan & & 23.000 & 15.000 \\
\hline & $\begin{array}{l}\text { Persentase marjin } \\
\text { keuntungan }\end{array}$ & & $15,75 \%$ & $9,49 \%$ \\
\hline Konsumen & Harga beli & 160.000 & 146.000 & 158.000 \\
\hline \multicolumn{2}{|c|}{ Marjin pemasaran } & 0 & 23.000 & 15.000 \\
\hline
\end{tabular}

Sumber : diolah data primer (2017)

Pada tabel 1 pada produk sokasi saluran I hasil marjin pemasarannya Rp 0 karena tidak melalui lembaga pemasaran dan langsung ke konsumen, saluran pemasaran II menghasilkan marjin pemasaran sebesar Rp 72.000,- dan untuk marjin pemasaran saluran III menghasilkan sebesar Rp 74.000,-. Marjin keuntungan ditingkat produsen diperoleh sebesar 76,39\% dari $100 \%$ untuk saluran I. Saluran yang paling kecil marjin keuntungannya adalah saluran III karena banyak lembaga saluran pemasaran yang terlibat untuk ditingkat lembaga yaitu ditingkat produsen diperoleh sebesar 10,52\% dari $100 \%$.

Pada tabel 2 untuk saluran I tempat nasi menghasilkan marjin pemasaran Rp 0 karena langsung ke konsumen tanpa melalui lembaga pemasaran, saluran II menghasilkan sebesar Rp. 17.000,- dan saluran pemasaran III menghasilkan Rp 23.000,. Marjin keuntungan di tingkat produsen diperoleh sebesar 51,87\% dari $100 \%$ untuk saluran I. Saluran yang paling kecil marjin keuntungannya adalah saluran III karena banyak lembaga saluran pemasaran yang terlibat untuk ditingkat lembaga yaitu ditingkat pedagang besar diperoleh sebesar $5,71 \%$ dari $100 \%$. 
Tabel 2.

Marjin Pemasaran dan Marjin Keuntungan pada Produk Sokasi di Desa Kayubihi, Kecamatan Bangli, Kabupaten Bangli.

\begin{tabular}{|c|c|c|c|c|}
\hline \multirow[b]{2}{*}{ Pelaku Pasar } & \multirow[b]{2}{*}{ Jenis Harga } & \multicolumn{3}{|c|}{ Distribusi Harga pada Pola Tataniaga (Rp/Produk) } \\
\hline & & Saluran I & Saluran II & Saluran III \\
\hline \multirow[t]{3}{*}{ Produsen } & Harga Jual & 66.500 & 53.000 & 53.000 \\
\hline & Marjin keuntungan & 122.230 & 36.230 & 46.230 \\
\hline & $\begin{array}{l}\text { Persentase marjin } \\
\text { keuntungan }\end{array}$ & $76,39 \%$ & $48,95 \%$ & $55,03 \%$ \\
\hline \multirow[t]{3}{*}{ Pengepul } & Harga beli & & 53.000 & 53.000 \\
\hline & Marjin keuntungan & & 48.240 & 49.240 \\
\hline & $\begin{array}{l}\text { Persentase marjin } \\
\text { keuntungan }\end{array}$ & & $39,21 \%$ & $39,70 \%$ \\
\hline \multirow{3}{*}{$\begin{array}{l}\text { Pedagang } \\
\text { besar }\end{array}$} & Harga beli & & & 66.000 \\
\hline & Marjin keuntungan & & & 18.200 \\
\hline & $\begin{array}{l}\text { Persentase marjin } \\
\text { keuntungan }\end{array}$ & & & $13,00 \%$ \\
\hline \multirow[t]{3}{*}{ Pengecer } & Harga beli & & 123.000 & 70.000 \\
\hline & Marjin keuntungan & & 23.000 & 15.000 \\
\hline & $\begin{array}{l}\text { Persentase marjin } \\
\text { keuntungan }\end{array}$ & & $15,75 \%$ & $9,49 \%$ \\
\hline Konsumen & Harga beli & 66.500 & 70.000 & 76.000 \\
\hline \multicolumn{2}{|c|}{ Marjin pemasaran } & 0 & 17.000 & 23.000 \\
\hline
\end{tabular}

Sumber : diolah data primer (2017)

Pada tabel 3 marjin pemasaran pada produk tempat kue untuk saluran pemasaran I yaitu Rp 0 karena langsung ke konsumen tanpa melalui lembaga yang lain, saluran II adalah Rp. 11.000,- dan untuk saluran III sebesar Rp 17.000,-. Marjin keuntungan di tingkat produsen diperoleh sebesar $40,77 \%$ dari $100 \%$ untuk saluran I. saluran yang paling kecil marjin keuntungannya adalah saluran III.

Tabel 3.

Marjin Pemasaran dan Marjin Keuntungan pada Produk Tempat Nasi di Desa Kayubihi, Kecamatan Bangli, Kabupaten Bangli

\begin{tabular}{llccc}
\hline \multirow{2}{*}{ Pelaku Pasar } & Jenis Harga & \multicolumn{2}{c}{ Distribusi Harga pada Pola Tataniaga (Rp/Produk) } \\
\cline { 2 - 5 } Produsen & Harga Jual & Saluran I & Saluran II & Saluran III \\
& Marjin keuntungan & 30.000 & 19.000 & 19.000 \\
& Persentase marjin & 12.230 & 1.230 & 1.230 \\
& keuntungan & $40,77 \%$ & $6,47 \%$ & $6,47 \%$ \\
\hline Pengepul & Harga beli & & & \\
& Marjin keuntungan & & 19.000 & 19.000 \\
& & & 10.240 & 5.240
\end{tabular}




\begin{tabular}{llcr} 
& Persentase marjin & $36,66 \%$ & $24,00 \%$ \\
\hline $\begin{array}{l}\text { keuntungan } \\
\text { besar }\end{array}$ & Harga beli & & \\
& Marjin keuntungan & & 25.000 \\
& Persentase marjin & & 5.200 \\
& keuntungan & & $17,00 \%$ \\
\hline Pengecer & Harga beli & & \\
& Marjin keuntungan & & 31.000 \\
& Persentase marjin & & 5.000 \\
& keuntungan & & $16,22 \%$ \\
\hline Konsumen & Harga beli & & \\
\hline \multicolumn{2}{c}{ Marjin pemasaran } & & 36.000 \\
\hline
\end{tabular}

Sumber : data primer diolah (2017)

\section{Kesimpulan dan Saran}

\subsection{Kesimpulan}

Desa Kayubihi memiliki lima jenis tanaman bambu yaitu Bambu Tali, Bambu Buluh Gading, Bambu Buluh Lengis, Bambu Betung, dan Bambu Jajang Aya, kelima jenis bambu tersebut menghasilkan dibawah 200 rumpun/ha yang artinya belum berpotensi, produk utama yang dihasilkan adalah sokasi, tempat kue, dan tempat nasi. Saluran pemasaran ketiga produk utama menghasilkan masing - masing tiga saluran pemasaran, marjin pemasaran yang paling pendek yaitu saluran I karena tanpa melalui saluran pemasaran yang lain atau langsung ke konsumen akhir dan marjin keuntungan yang paling banyak diperoleh adalah saluran I ditingkat lembaga produsen.

\subsection{Saran}

Hasil data potensi bambu di Desa Kayubihi menunjukan potensi yang rendah sehingga perlu ditingkatkan potensi yang ada di Desa Kayubihi.

\section{Ucapan Terimakasih}

Penulis mengucapkan terimakasih kepada semua pihak yang sudah membantu dalam penelitian ini, hingga termuat dalam e-jurnal.

\section{Daftar pustaka}

Antara, M. 2006. Bahan Ajar Kuliah Metode Penelitian Agribisnis. Program Studi Magister Agribisnis. Program Pasca Sarjana Universitas Udayana. Denpasar.

Arinasa K, Nyoman Peneng. 2014. Jenis - jenis Bambu di Bali dan Potensinya. Lipi. Jakarta.

Batubara, R. 2002. Pemanfaatan Bambu di Indonesia http://library.usu.ac.id/download//fp/hutan-ridwanti4/pdf. (12 Desember 2016)

BPS Provinsi Bali. 2013. Sensus Pertanian Tahun 2013. Badan Statistik Provinsi Bali. Denpasar. 
Departemen Kehutanan dan Perkebunan.1998. Keputusan Mentri Kehutanan dan Perkebunan.

Dinas Pertanian Bangli Kabupaten Bangli. 2016. Hasil Produksi tanaman bambu di Kecamatan Bangli Kabupaten Bangli.

Gunardja, E. 1995. Strategi Penelitian Bambu. Rubik Tinjauan Pustaka. Jurnal PPT Vol I No 4. 1995

Ridho, Alamsyah. 2010. Analisis potensi ketersediaan dan pemasaran bambu Belangke (Gigantochloas Pruriens Widjaja) di Hutam Rakyat Bambu Desa Timbang Lawan, Kecamatan Bahorok, Kabupaten Langkat dalam Industri Dupa Bambu. Skripsi Departemen Manajemen Hutan Universitas Sumatra Utara.

Rijai, L. 2003. Bioprospeksi Suatu Paradigma Baru Dalam Pengelolaan Hutan Berkelanjutan. Institut Pertanian Bogor. Bogor

Sevilla, et.al. 1994. Pengantar Metode Penelitian. Universitas Indonesia. Jakarta

Kohls, R.L and Joseph N. U. 1998. Marketing of Agricultural Product.Fifth Edition. Collier Macmillan International Edition. New York. 